\title{
Construction of a chalcone reductase expression vector and transformation of soybean plants
}

\author{
NAN WU, PI-WU WANG, NAN LIN, SHI LU, YONG-QI FENG, JIE RONG, ZHUO ZHANG and JING QU \\ Plant Biotechnology Center, Agronomy Courtyard, Jilin Agricultural University, Changchun, Jilin 130118, P.R. China
}

Received May 24, 2016; Accepted June 19, 2017

DOI: $10.3892 / \mathrm{mmr} .2017 .7382$

\begin{abstract}
The present study aimed to clone the soybean chalcone reductase $3(\mathrm{CHR} 3)$ and create a recombinant expression vector pCAMBIA3300-CHR3 containing Bar resistance gene as a selection marker, and then obtain transgenic soybean plants using Agrobacterium infection. The plant expression vector pCAMBIA3300-CHR3 was transferred into soybean receptor plants, Jinong 17 and Jilin 30. Polymerase chain reaction (PCR) and Southern blotting were used to confirm the positive transgenic plants. Additionally, reverse transcription-quantitative PCR (RT-qPCR) was used to detect $C H R 3$ expression and isoliquiritigenin content was measured using high-performance liquid chromatography (HPLC) in the transgenic offspring. Soybean CHR3 (932 bp fragment) was successfully cloned into the plant expression vector pCAMBIA3300-CHR3, which was subsequently transferred into soybean receptor plants. In the T1 generation positive plants were validated by PCR analysis, including eight Jinong 17 and five Jilin 30 transgenic plants; Southern blotting demonstrated that the functional components of the pCAMBIA3300-CHR3 vector had been integrated into the soybean genome; RT-qPCR results demonstrated that the expression of CHR 3 mRNA was increased by 2 to 20 -fold in the transgenic plants compared with the non-transgenic soybean plants. Furthermore, the isoliquiritigenin content was increased by $8.56 \%$ in the transgenic Jinong 17 , compared with control plants, as detected by HPLC. The CHR3 gene can produce isoliquiritigenin, a precursor of daidzein, which in turn can improve the ability of soybean to resist phytophthora root rot.
\end{abstract}

\section{Introduction}

Flavonoids are an important class of secondary metabolites present in soybean. They have important physiological functions, such as antifungal and antioxidation. They can inhibit

Correspondence to: Dr Pi-Wu Wang, Plant Biotechnology Center, Agronomy Courtyard, Jilin Agricultural University, 2888 Park Avenue, Changchun, Jilin 130118, P.R. China

E-mail: qujing_06@163.com

Key words: soybean chalcone reductase, expression vector, isoliquiritigenin content the growth of microorganisms and promote the growth of the soybean (1). Soybean glycosides are one of the components of isoflavones and are important physiologically active substances (2). A study has reported that chalcone reductase (CHR) is required for the synthesis of precursors of soybean glycosides; CHR synthesizes isoliquiritigenin, a precursor to daidzein (3). For the synthesis of daidzein, cinnamic amide is first formed from phenylalanine under the action of phenylalanine lyase and then catalyzed by 4-hydroxycinnamamidase to coumaric acid. Coumaric acid coenzyme A ligase (4CL) effects the conversion to the coumarin coenzyme A. Coumarin coenzyme A is a common precursor of daidzein and genistein synthesis. In the synthesis pathway of daidzein, CHR and chalcone synthase combine to catalyze the synthesis of allyl coenzyme A. Glycyrrhizin is catalyzed by chalcone isomerase to produce licorice and licorice is catalyzed by isoflavone synthase (IFS) to synthesize daidzein.

Soybean glycosides have certain biological effects that genistein does not. Soybean glycosides have various beneficial effects, including preventing breast cancer (4), improving immunity (5), preventing skin burns caused by ultraviolet radiation (6) and the treatment of women with postpartum depression (7). They have an important role in protecting against soybean Phytophthora root rot $(8,9)$.

There are multiple forms of $C H R$ gene in the soybean genome (10). A previous study report identified five $C H R$ genes (11). Besides the CHRl gene, the function of the others has not been fully characterized $(12,13)$. Graham et al (14) verified $4 \mathrm{CHR}$ gene fragments using RNAi technology, and demonstrated that not all of the CHR proteins were involved in the synthesis of soybean glycosides. In 2009, Liu (15) isolated a new $C H R$ gene in soybean. Based on the previous research, the type and quantity of $C H R$ genes present in soybean is inconclusive. Therefore, $C H R$ gene cloning and identification are also the important for understanding the regulation of glycoside synthesis in soybean.

In the current study, a $C H R 3$ gene expression vector was constructed, and transformed into soybean varieties to overexpress $C H R 3$. Subsequently, the effects of $C H R 3$ on the synthesis of soybean glycosides were analyzed, the function and efficiency of different $C H R$ genes were identified and the mechanism of CHR action in the synthesis of soybean glycosides was determined, which lays a theoretical foundation for breeding soybean resistant to Phytophthora root rot by using 
genetic engineering technology to control the synthesis and metabolism of soybean glycosides.

\section{Materials and methods}

Materials. Soybean varieties 'Jinong 17' and 'Jilin 30', E. coli DH5 $\alpha$, Agrobacterium tumefaciens strain EHA105, pMD18-T cloning vector, the recombinant prokaryotic expression vector BL21-pET28a and expression vector pCAMBIA3300 were all provided and maintained by the Plant Biotechnology Center of Jilin Agricultural University (Changchun, China).

Obtaining the objective fragment. The BL21-pET28a-CHR3 recombinant expression plasmid, which was cloned by Zhang et al (16) (GenBank accession no: KF927169), was used as the template, and objective fragment was amplified using specific primers CHR3 sense/CHR3 antisense (Table I) and sequenced by the NCBI (National Institutes of Health, Bethesda, MD, USA).

The polymerase chain reaction (PCR) amplification system was as follows: $2.5 \mu 1 \mathrm{MgCl}_{2}, 2.5 \mu \mathrm{l} 10 \mathrm{X}$ Taq buffer, $1 \mu 1$ specific primer, $1 \mu 1$ template, $0.5 \mu \mathrm{l} \mathrm{dNTP}, 0.2 \mu \mathrm{l}$ Taq polymerase (reagents from Takara Biotechnology Co., Ltd., Dalian, China), sterile water was added up to $25 \mu \mathrm{l}$. Amplification conditions were as follows: $94^{\circ} \mathrm{C}$ predenaturation for $10 \mathrm{~min}$, then $94^{\circ} \mathrm{C}$ denaturation for $30 \mathrm{sec}, 55^{\circ} \mathrm{C}$ renaturation for $40 \mathrm{sec}$ and $72^{\circ} \mathrm{C}$ extension for $50 \mathrm{sec}$ for 35 cycles; a final $72^{\circ} \mathrm{C}$ extension for $10 \mathrm{~min}$ was performed and then maintained at $4^{\circ} \mathrm{C}$. PCR products were separated by $1 \%$ agarose gel electrophoresis, and then ligated into the pMD18-T vector following recovery from the gel (DNA gel extraction kit; Takara Biotechnology Co., Ltd.). The mixture was: $5 \mu \mathrm{l} \mathrm{CHR3,} 1 \mu \mathrm{l}$ solution I and $4 \mu \mathrm{l}$ pMD18-T at $16^{\circ} \mathrm{C}$ overnight. Recombinant cloning vector pMD18-T-CHR3 was transformed into competent cells E. coli $\mathrm{DH} 5 \alpha$, and then monoclonal colonies were selected and sequenced by Comate Bioscience Co., Ltd., (Changchun, China).

Construction of overexpression vector of CHR3 gene. The CHR3 gene fragment was amplified by PCR as described above and its products were separated by $1 \%$ agarose gel electrophoresis, and obtaining purified target fragments. Following electrophoresis, the gel was placed under UV light and the target gel cut out with a knife and placed in tubes and the AxyPrep DNA Gel Extraction kit (Corning Life Sciences Limited. Wujiang, China) employed. Fragment and the objective based expression vector pCAMBIA3300 were digested with SacI and BamHI (restriction endonucleases from Takara Biotechnology Co., Ltd.), and the enzyme digestion system was as follows: $2 \mu \mathrm{l}$ SacI, $1 \mu \mathrm{l}$ BamHI, $8 \mu \mathrm{l}$ carrier (fragment), $2 \mu \mathrm{l} 10 \mathrm{X} \mathrm{BamHI}$ buffer and $7 \mu \mathrm{l}$ $\mathrm{DDH}_{2} \mathrm{O}$; these were incubated at $37^{\circ} \mathrm{C}$ for $2 \mathrm{~h}$, and inactivated at $80^{\circ} \mathrm{C}$. Enzyme digestion products were separated by $1 \%$ agarose gel electrophoresis, and then the vector and the target fragment were collected and ligated in the following system: $4.5 \mu \mathrm{l} \mathrm{CHR3}$ DNA fragment, $2.5 \mu \mathrm{l}$ pCAMBIA3300 vector, $1 \mu 1$ T4 ligase,

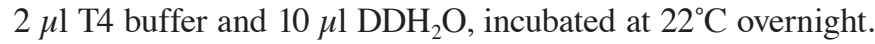
The expression vector pCAMBIA3300-CHR3 was produced and anti-herbicide Bar gene used as a screening marker. The recombinant expression vector was identified by PCR and double enzymic digestion.
Genetic transformation of soybean. In this experiment, the pCAMBIA3300-CHR3 DNA was transferred into the receptor soybean cultivar Jinong 17 and Jilin 30 by Agrobacterium infection $(17,18)$, thus obtaining positive plants. At the time of Agrobacterium infection, only the T-DNA region was transferred into the recipient soybean, with the Bar gene as the marker gene, thereby obtaining a positive plant with herbicide resistance.

\section{Progeny analysis of transgenic plants}

PCR detection. The pCAMBIA3300 plasmid vector contained constitutive promoters $35 S$ and marker gene Bar. Primers for the resistance gene $\operatorname{Bar}(552 \mathrm{bp}$ ) and promoter $35 S$ (500 bp) sequences (Bar sense/Bar antisense and $35 \mathrm{~S}$ sense/35S antisense) were designed by Primer software version 5.00 (Premier Biosoft International, Palo Alto, CA, USA; Table I).

A Nuclean Plant Genomic DNA kit (CW Biotech, Beijing, China) was used to extract genomic DNA from young soybean leaves, and the soybean leaves genome of untransformed plants were used as a negative control. The PCR reaction volume for Bar was $25 \mu \mathrm{l}: 2.5 \mu \mathrm{lgCl}_{2}, 2.5 \mu \mathrm{l}$ Buffer, $1 \mu \mathrm{l}$ BarS, $1 \mu 1$ BarAS, $1 \mu 1$ genome DNA, $0.8 \mu 1$ dNTP, $0.2 \mu 1$ Taq and $\mathrm{DDH}_{2} \mathrm{O}$ to $25 \mu \mathrm{l}$. The $\mathrm{PCR}$ reaction conditions were as follows: $94^{\circ} \mathrm{C}$ predenaturation for $5 \mathrm{~min}, 94^{\circ} \mathrm{C}$ denaturation for $40 \mathrm{sec}, 60^{\circ} \mathrm{C}$ renaturation for $40 \mathrm{sec}$ and $72^{\circ} \mathrm{C}$ extension for $40 \mathrm{sec}$ for 30 cycles; the last extension step was at $72^{\circ} \mathrm{C}$ for $8 \mathrm{~min}$ and then maintained at $4^{\circ} \mathrm{C}$. The PCR reaction volume for $35 \mathrm{~S}$ was $25 \mu \mathrm{l}: 2.5 \mu \mathrm{l} \mathrm{MgCl}_{2}, 2.5 \mu \mathrm{l}$ Buffer, $1 \mu \mathrm{l}$ 35S, $1 \mu \mathrm{l}$ 35AS, $1 \mu \mathrm{l}$ genome DNA, $0.8 \mu \mathrm{l}$ dNTP, $0.2 \mu \mathrm{l} \mathrm{Taq}$ and $\mathrm{DDH}_{2} \mathrm{O}$ to $25 \mu \mathrm{l}$. The reaction conditions of PCR were: $94^{\circ} \mathrm{C}$ predenaturation for $5 \mathrm{~min}, 94^{\circ} \mathrm{C}$ denaturation for $30 \mathrm{sec}$, $55^{\circ} \mathrm{C}$ renaturation for $30 \mathrm{sec}$ and $72^{\circ} \mathrm{C}$ extension for $30 \mathrm{sec}$ for 40 cycles; a final extension step was performed at $72^{\circ} \mathrm{C}$ for $8 \mathrm{~min}$, and then maintained at $4^{\circ} \mathrm{C}$. PCR products were separated by $1 \%$ agarose gel electrophoresis and sequenced after recovery using a AxyPrep DNA Gel Extraction kit (Corning Life Sciences, Wujiang, China).

Southern blotting detection of transgenic plants. PCR was performed for the initial detection of the target gene integration and to identify positive plants for Southern blotting to further verify the integration of the target gene at the genome level. This enabled the number of copies of the gene of interest in the genome to be detected.

The genomic DNA of positive T1 generation transgenic plants was extracted using a Nuclean Plant Genomic DNA kit (CW Biotech, Beijing, China) and then digested using BamHI. Southern blotting was conducted with probe labeling, sample preparation, transfer of DNA to membrane, hybridization, washing the membrane and signal development performed according to the manufacturer's protocols. Purified 35S DNA (https://www.ncbi.nlm.nih.gov/nucleot ide/1050047859?report=genbank\&log $\$=$ nuclalign\&blast rank=1\&RID=NXN567FN014) was used as the DNA probe and the DIG High Primer DNA Labeling and Detection Starter kit I (Roche Diagnostics, Basel, Switzerland) was used.

\section{Reverse transcription-quantitative PCR (RT-qPCR) detection} of transgenic plants. Total RNA was extracted from leaves of transgenic plants which were detected by Southern blotting. These plants were tested by RT-qPCR to verify the integration 
Table I. Primers of different genes used for cloning and reverse transcription-quantitative polymerase chain reaction.

\begin{tabular}{lll}
\hline Name & \multicolumn{1}{c}{ Sequence (5'-3') } & Product (bp) \\
\hline CHR3 sense & CCCGAGCTCTTCAGGACACAAATGCCA & CHR3 (932) \\
CHR3 antisense & TTTGGATCCCTAAACGTCTCCATCCC & \\
35S sense & TAGAGGACCTAACAGAAC & 35S (500) \\
35S antisense & CCGTGTTCTCTCCAAATG & \\
Bar sense & TCAAATCTCGGTGACGGGC & Bar (552) \\
Bar antisense & ATGAGCCCAGAACGACGC & \\
Q-CHR3 sense & GGTGGGTTACCGTCATTTTG & \\
Q-CHR3 antisense & TCATGTCTCAGCCTCACTGG & \\
Q-ACT forward & ATCTTGACTGAGCGTGGTTATTCC & \\
Q-ACT reverse & GCTGGTCCTGGCTGTCTCC &
\end{tabular}

SacI (CHR3 sense) and BamHI (CHR3 antisense) enzyme cleave sites are underlined. CHR3, chalcone reductase 3; Q-, qPCR primer; ACT, $\beta$-actin.

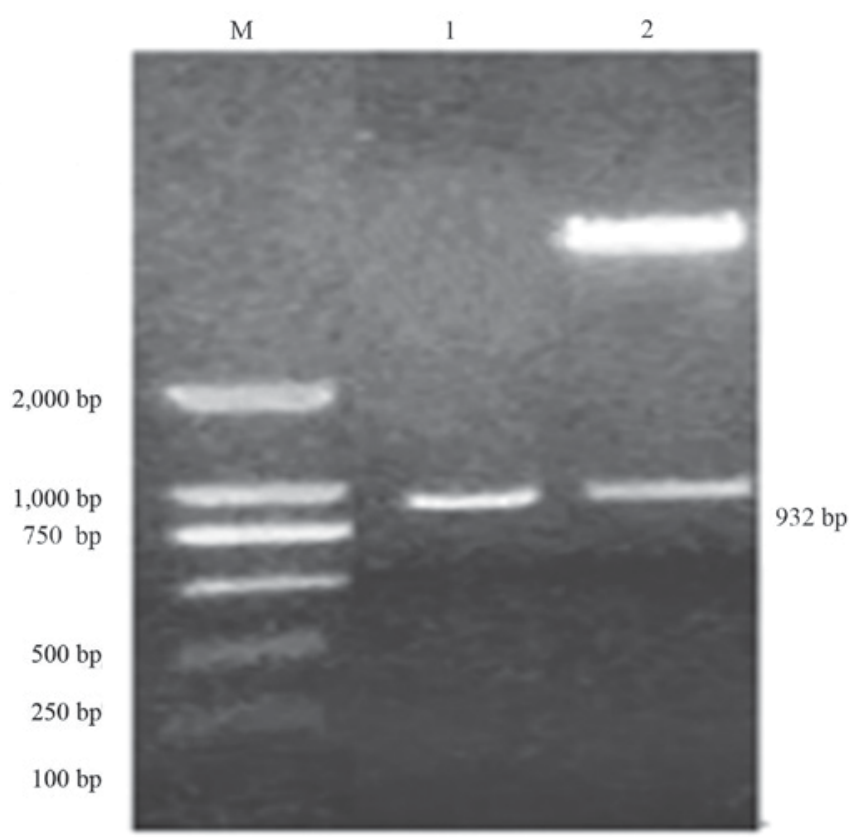

Figure 1. pCAMBIA3300-CHR3 overexpression vector. M, DL2000 DNA marker; 1, CHR3 polymerase chain reaction product; 2 , double enzyme digestion ( $\mathrm{SaCI}$ and BamHI). CHR3, chalcone reductase 3.

of the target gene at the mRNA level. A Total RNA Extraction kit (Omega Bio-Tek, Inc., Norcross, GA, USA) was used and then reverse transcribed into cDNA using the All-in-One ${ }^{\mathrm{TM}}$ First-Strand cDNA Synthesis kit (GeneCopoeia, Inc., Rockville, MD, USA). The reaction volume was $25 \mu \mathrm{l} ; 1 \mu \mathrm{g} 250 \mu \mathrm{M}$ Total RNA, $1 \mu \mathrm{l} 60 \mu \mathrm{M}$ Random Primer, $1 \mu \mathrm{l}$ Oligo(dT) $)_{18}$ and $\mathrm{DDH}_{2} \mathrm{O}$ to $13 \mu 1$, heated to $65^{\circ} \mathrm{C}$ for $10 \mathrm{~min}$ and put in an ice bath. Then was added $5 \mu \mathrm{l} 25 \mathrm{mM} 5 * \mathrm{RT}$ Reaction Buffer, $1 \mu \mathrm{l}$ 25 U dNTP, $1 \mu 1200$ U RNase Inhibitor, $1 \mu 1$ M-MLV RTase and $\mathrm{DDH}_{2} \mathrm{O}$ to $25 \mu \mathrm{l}$. This was diluted 5 -fold for subsequent use. The RT-qPCR primer sequences for CHR3 (Q-CHR3) are presented in Table I. Soybean $\beta$-actin gene (GenBank accession number: NM_001252731.2) was selected as the reference gene and appropriate primers were designed (Q-ACT; Table I). The total cDNA of the soybean leaf tissue was analyzed by 3000P Mx fluorescence Real-time RT-qPCR instrument (Agilent StrataGene Mx3000P) $(19,20)$ according to the protocols of the SYBR Premix Ex Taq ${ }^{\mathrm{TM}}$ kit (Takara Biotechnology Co., Ltd.). The PCR amplification system was as follows: $12.5 \mu 12 \mathrm{X}$ SYBR Premix Ex Taq polymerase, $1 \mu \mathrm{l}$ Q-CHR3 sense primer, $1 \mu \mathrm{l}$ Q-CHR3 reverse primer, $2 \mu \mathrm{l}$ cDNA and sterile water to $25 \mu \mathrm{l}$. PCR amplification conditions were as follows: $95^{\circ} \mathrm{C}$ predenaturation for $3 \mathrm{~min}$, followed by 40 cycles of $95^{\circ} \mathrm{C}$ denaturation for $10 \mathrm{sec}$ and $60^{\circ} \mathrm{C}$ reaction for $35 \mathrm{sec}$. Analysis of relative gene expression data was performed by the $2^{-\Delta \Delta C q}$ method $(21,22)$.

Determination of isoliquiritigenin production. The content of isoliquiritigenin was measured using high-performance liquid chromatography (HPLC). Soybean leaves were treated at $70^{\circ} \mathrm{C}$ to dry them, and untransformed soybean leaves were used as the control. Leaves $(0.5 \mathrm{~g}$ dry weight) were ground to a fine powder in liquid nitrogen and dissolved in methanol (methanol: sample 4:1 $\mathrm{v} / \mathrm{v}$ ), and then exposed to ultrasonic treatment at $40^{\circ} \mathrm{C}$ for $50 \mathrm{~min}$ following soaking overnight in methanol. Ethyl acetate was used to extract the distribution of the isoliquiritigenin in the enzyme hydrolysate, and then the ethyl acetate was extracted. The sample was dissolved in methanol solution, and filtered using a $0.22 \mu \mathrm{m}$ organic membrane. A $20 \mu \mathrm{l}$ sample volume was analyzed using HPLC $(23,24)$. A Shimadzu LC-20AT HPLC system (Shimadzu Corporation, Kyoto, Japan) was used. Detection was performed with a fluorescence spectrometer (Beijing Jitian Instrument Co., Ltd., Beijing, China) with excitation at $366 \mathrm{~nm}$ and emission at $417 \mathrm{~nm}$. The C18 column (GL Sciences Inc., Tokyo, Japan; $5 \mu \mathrm{m}$, $4.6 \times 150 \mathrm{~mm}$ ) was used at room temperature. The mobile phase was methanol: $\mathrm{H}_{2} \mathrm{O}$ 80:20 (0-5 min, 30\% methanol; 5-20 min, 45\% methanol; $20-30 \mathrm{~min}, 45 \%$ methanol; $30-35 \mathrm{~min}, 30 \%$ methanol; and, 35-40 min, 30\% methanol). The flow rate was $0.8 \mathrm{ml} / \mathrm{min}$.

Statistical analysis. Significant differences of $\mathrm{CHR} 3$ gene expression between the transgenic plants and the non-transformed plants determined by RT-qPCR were analyzed by 
A
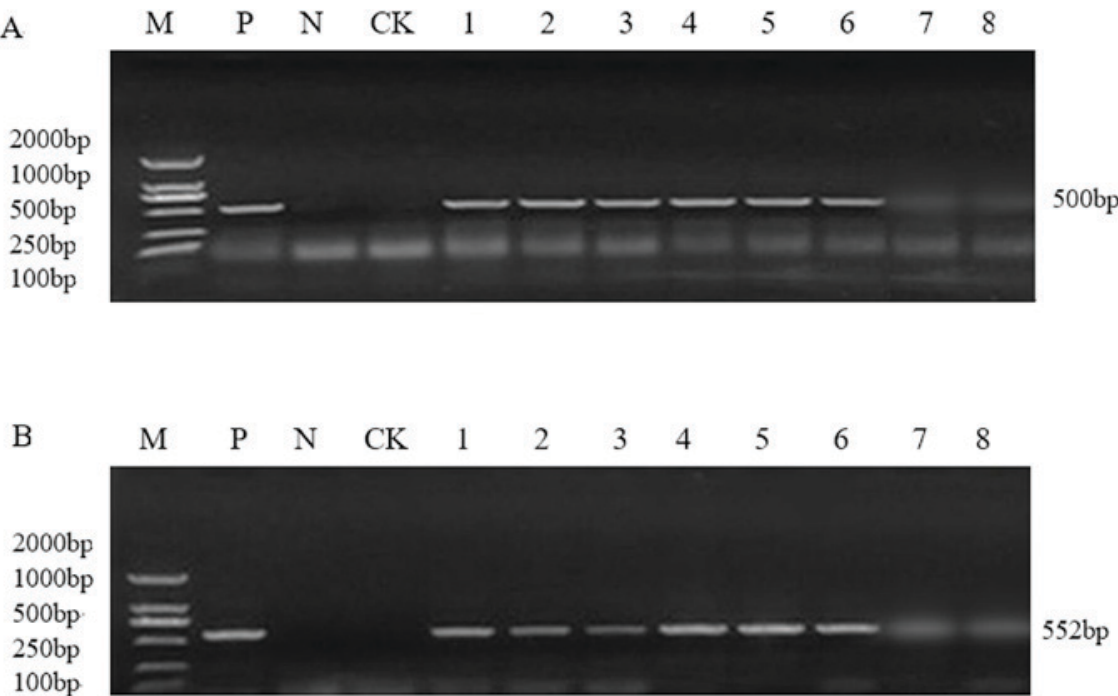

Figure 2. Detection of (A) $35 S$ and (B) herbicide resistant Bar in T1 generation Jinong 17 plants. M, DL2000 DNA marker; P, positive control (pCAMBIA3300-CHR3 DNA); $\mathrm{N}$, negative control $\left(\mathrm{DDH}_{2} \mathrm{O}\right)$; $\mathrm{CK}$, non-transformed plant; 1-8, transgenic plants.
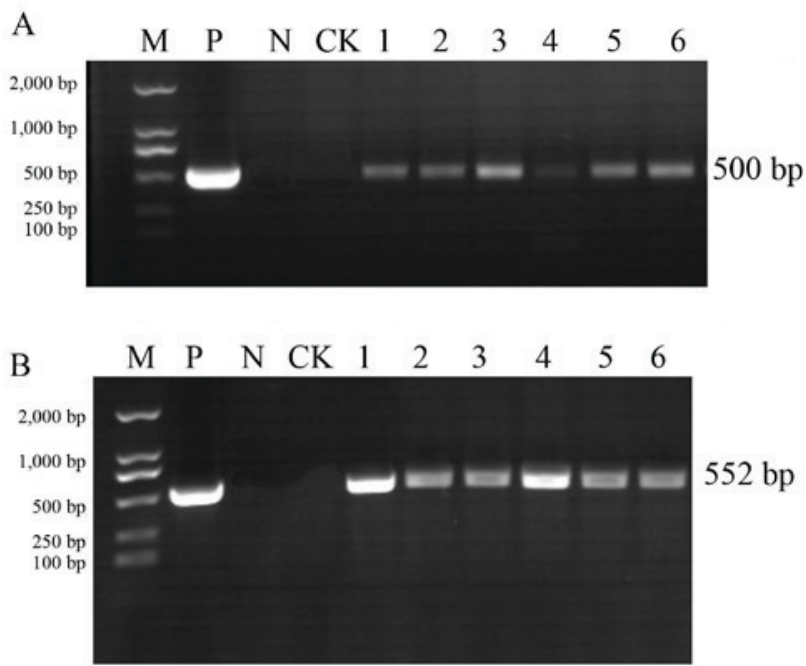

Figure 3. Detection of (A) $35 \mathrm{~S}$ and (B) herbicide resistant Bar in T1 generation Jilin 30 plants. M, DL2000 DNA marker; P, positive control; N, negative control; CK, non-transformed plant; 1-6, transgenic plants.

one-way analysis of variance followed by LSD post hoc test using SPSS version 19.0 (IBM Corp., Armonk, NY, USA). $\mathrm{P}<0.05$ was considered to indicate a statistically significant difference.

\section{Results}

Cloning of soybean chalcone reductase gene CHR3 fragment and construction of over expression vector. Cloned BL21-pET28a-CHR3 plasmid was used as the template, and the objective fragment was amplified using specific primers (CHR3 sense/CHR3 antisense). The amplified fragment length was $932 \mathrm{bp}$. The amplified fragment was cloned into pCAMBIA3300 to obtain an overexpression vector,
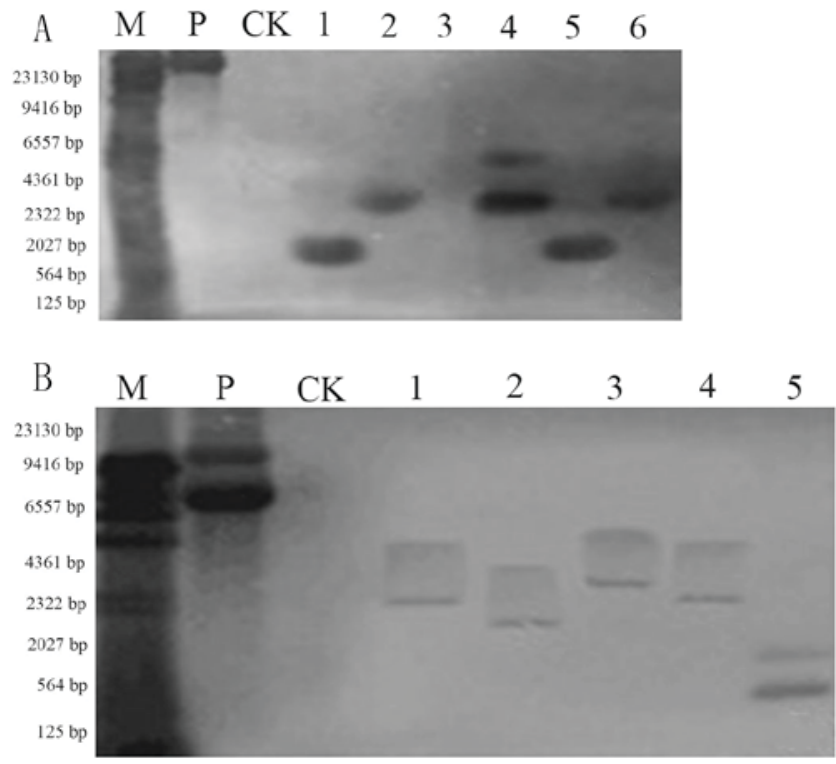

Figure 4. Southern blotting detection of $35 \mathrm{~S}$ T1 positive plants. M, DNA marker; P, positive control; CK, non-transformed plant; (A) 1-6, Jinong 17 transgenic plants; (B) 1-5, Jilin 30 transgenic plants.

pCAMBIA3300-CHR3. The target fragment was 932 bp was identified using $\mathrm{SacI} / \mathrm{BamHI}$ double enzyme digestion. As presented in Fig. 1, results of PCR and double enzyme digestion were consistent with the expected size, demonstrating the success of vector construction.

Creation and detection of $T 1$ generation transgenic plants $P C R$ analysis of $T 1$ generation plants. The pCAMBIA3300-CHR3 overexpression vector was transferred into the soybean varieties Jinong 17 and Jilin 30. There were four positive Jinong 17 plants in the T0 generation and two positive Jilin 30 plants in theT0 generation, as detected by PCR. From the T0 generation, 45 Jinong 17 seed grains were 

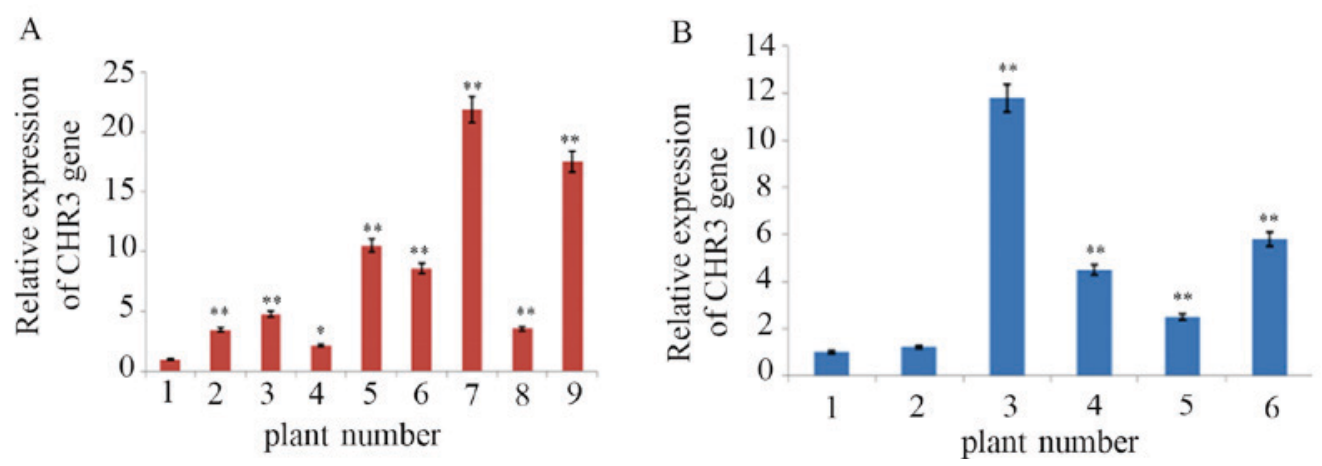

Figure 5. Relative expression of $C H R 3$ gene. (A) Relative expression of $C H R 3$ in Jinong 17. 1, non-transformed plant; 2-9, transgenic plants. (B) Relative expression of Jilin 30. 1, non-transformed plant; 2-6, transgenic plants. Data are mean \pm standard deviation. ${ }^{*} \mathrm{P}<0.05$ and ${ }^{* *} \mathrm{P}<0.01$ vs. non-transformed plant. CHR3, chalcone reductase 3 .
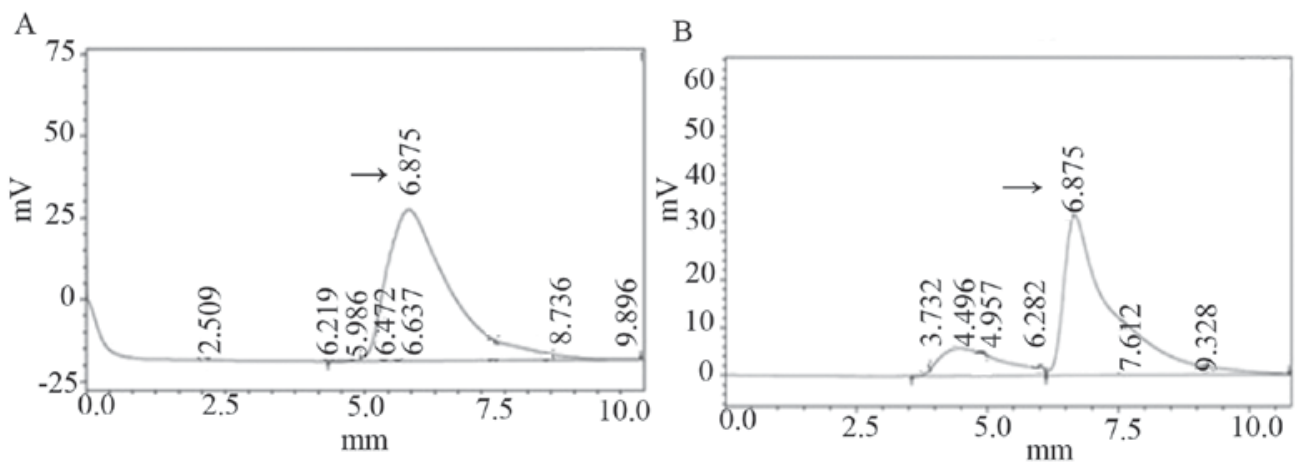

Figure 6. HPLC detection of isoliquiritigenin. HPLC analysis of the isoliquiritigenin in the (A) non-transformed soybean and (B) transformed soybean Jinong 17 plant 6 . The peak of the arrow refers to the content of isoliquiritigenin. HPLC, high-performance liquid chromatography.

harvested and18 Jilin 3018 grains were harvested. Genomic DNA was extracted from $\mathrm{T} 1$ generation plants, and $35 \mathrm{~S}$ promoter sequences and the Bar gene were detected by PCR using specific primers (Figs. 2 and 3). Recombinant expression plasmid DNA vector pCAMBIA3300-CHR3 was the positive control and the untransformed receptor soybean plants were a negative control.

As presented in Figs. 2 and 3, PCR analysis of the T1 generation transgenic plants produced the amplified $35 S$ and Bar bands at the correct estimated size $(35 S, 500 \mathrm{bp}$; Bar, 552 bp). Among them, Jinong 17 had 8 positive strains (Fig. 2) and Jilin 30 had 6positive strains (Fig. 3).

Southern blot analysis of T1 plants. Genomic DNA of positive transgenic plants was extracted and digested with BamHI. Southern blotting was performed using the purified 35S DNA as a probe. As presented in Fig. 4, the non-transformed plant did not produce hybridization signals. There was observable hybridization in Jinong 17 (Fig. 4A) and Jilin 30 (Fig. 4B) transgenic plants. The Southern blotting indicated that the functional components were integrated into the soybean genome, but that the integration site was not the same in each plant.

RT-qPCR detection of transgenic plants. Positive transgenic plants detected using Southern blotting were analyzed by RT-qPCR with SYBR Green I. As presented in Fig. 5, the relative expression $\mathrm{CHR} 3 \mathrm{mRNA}$ in transgenic soybean plants was significantly increased compared with control plants, and the difference ranged from 2 to 20 -fold.

The average relative expression of $C H R 3$ in the leaf tissue of transgenic Jinong17 plants 2-9 was 3.2, 4.8, 2.0, 10.2, 8.6, 20.0, 3.3 and 17.2-fold higher than in the non-transformed plant, respectively. The change in expression in transgenic plant 4 compared with the non-transformed plants reached a significance level of $\mathrm{P}<0.05$; others reached $\mathrm{P}<0.01$. The average relative expression of $\mathrm{CHR} 3$ in the leaf tissue of transgenic Jilin 30 plants $2-6$ was 1.2, 10.5, 4.3, 2.4 and 5.5-fold higher than in the non-transformed plants, respectively. $C H R 3$ expression was increased significantly in transgenic plants 3-6 compared with the non-transformed plant $(\mathrm{P}<0.01)$.

The isoliquiritigenin content of $T 1$ generation transgenic plants. The Jinong 17 plant 6 and non-transformed soybean leaf tissue were selected and their isoliquiritigenin content was measured by HPLC. According to the regression equation: $\mathrm{Y}=2,52828 \times 106 \mathrm{X}+0.223424, \mathrm{r}=0.999$ ( $\mathrm{X}$ represents the content of isoliquiritigenin; $\mathrm{Y}$ represents the peak area). As presented in Fig. 6A, isoliquiritigenin content of transformed plants was $1.256 \mu \mathrm{g} / \mathrm{ml}$; in Fig. 6B, the isoliquiritigenin content of untransformed plant leaf tissue was $1.157 \mu \mathrm{g} / \mathrm{ml}$. The isoliquiritigenin content was increased by $8.56 \%$ in transformed Jinong 17 plant 6; however, no obvious increase was observed in isoliquiritigenin content in the transgenic Jilin 30 plant compared with non-transformed plants. 


\section{Discussion}

Previous studies reported that there are five $C H R$ genotypes in alfalfa $(25,26)$. Young et al $(27)$ identified six $C H R$ genotypes in tribulus alfalfa. Shimada et al (28) cloned the polyketoreductase gene, that is homologous with the chalcone ketoreductase gene in Lotus japonicus, which was overexpressed in morning glory [Ipomoea nil (L.) Roth] suggesting it promotes isoliquiritigenin production. Li et al (12) cloned the CHRl gene, constructed an overexpression vector and transformed soybean plants. Tissues in the transgenic plants exhibited increased $C H R 1$ gene expression in soybean leaves. In the present study, RT-qPCR analysis demonstrated that the expression of $C H R 3$ was increased by $2-20$-fold in transgenic plants compared with non-transformed plants.

pCAMBIA3300-CHR3 was introduced into the soybean genome by Agrobacterium-mediated transformation, which was confirmed using Southern blotting. Zhang et al (16) cloned a $C H R 3$ gene from soybean and transformed into E. coli BL21, which expressed a protein that catalyzed the production of isoliquiritigenin in soybean powder. The expression of $\mathrm{CHR} 3$ in the transgenic Jinong 17 plant 6 was increased by 21.1-fold compared with control plants; however, isoliquiritigenin content was only increased by $8.56 \%$ in the present study, as detected by HPLC; the reason for this requires further investigation. Isoliquiritigenin is a precursor of daidzein, which in turn can improve the ability of soybean to resist phytophthora root rot.

\section{References}

1. Sun JM, Ding AL and Dong HR: High performance liquid chromatographic determination of isoflavone content in soybean test samples. Soybean Sci 19: 15-20, 2000 (In Chinese).

2. Wang Y, Wu L, Sun MY, Zhao X, Han YP, Teng WL and Li WB: Analysis of gene expression underlying soybean isoflavone synthesis relative enzymes at different growth stages. Soybean Sci 31: 887-893, 2012 (In Chinese).

3. Huang JX, Qu LJ, Yang J, Yin H and Gu HY: A preliminary study on the origin and evolution of chalcone synthase (CHS) gene in angiosperms. Acta Botanic Sinica 46: 10-19, 2004.

4. Choi EJ and Kim GH: Daidzein causes cell cycle arrest at the G1 and G2/M phases in human breast cancer MCF-7 and MDA-MB-453 cells. Phytomedicine 15: 683-690, 2008.

5. Gao Y, Gu W, Chen L, Xu Z and Li Y: The role of daidzein-loaded sterically stabilized solid lipid nanoparticles in therapy forcardio-cerebrovascular diseases. Biomaterials 29: 4129-4136, 2008.

6. Graham MY: The diphenylether herbicide lactofen induces cell death and expression of defense-related genes in soybean. Plant Physiol 139: 1784-1794, 2005.

7. Choi EJ and Kim GH: Daidzein causes cell cycle arrest at the G1 and G2/M phases in human breast cancer MCF-7 and MDA-MB-453 cells. Phytomedicine 15: 683-690, 2008.

8. Zhang Z, Lui ZK, Huang Z, Ma J, Yao D, Qu J and Wang PW: Isolation and functional characterization of soybean chalcone reductase gene Gmchr4. Chin J Oil Crop Sci 36: 720-727, 2014 (In Chinese)
9. Ren HL, Ma QB, Yang CY, Song EL, Wang RP, Ma TX, Tang YJ and Nian H: Identification of Phytophthora root rot disease of soybean breeding materials in South China. Soybean Sci 31: 453-456, 2012 (In Chinese).

10. Liu J, Todd TC and Trick HN: Rapid in plant evaluation of the root expressed transgenes in chimeric soybean plants. Plant Cell Rep 29: 113-123, 2010.

11. Oliver $\mathrm{Yu}$ and Brian McGonigle: Metabolic engineering of isoflavone biosynthesis. Advance Agronomy 86: 147-190,2005.

12. Li D, et al: Clone and transformation of chalcone reductase gene CHR1 in soybean. J Northwest Sci Tech Univ Agriculture Forestry (Social Science): 43, 2015.

13. Wu N, Wang P, Li D, Dai L, Zheng C, Lu S, Cai Y, Zhang Z, $\mathrm{Qu} \mathrm{J}$ and Xia H: Function of chalcone reductase gene CHR1 in soybean. Hereditas 36: 707-712, 2014.

14. Graham TL, Graham MY, Subramanian S and Yu O: RNAi silencing of genes for elicitation or biosynthesis of 5-deoxyisoflavonoids suppresses race-specific resistance and hypersensitive cell death in phytophthora sojae infected tissues. Plant Physiol 144: 728-740, 2007.

15. Liu GY: Isolation, sequence identification and tissue expression profile of two novel soybean (glycine max) genes-vestitone reductase and chalcone reductase. Mol Biol Rep 36: 1991-1994, 2009.

16. Zhang C, Wang PW, Zhang Z, et al: Clone of CHR3 and its activity analysis in vitro. J Northwest Sci Tech Univ Agriculture Forestry (Social Science): 43, 2015.

17. Zhu $\mathrm{C}, \mathrm{Wu} \mathrm{J}$ and $\mathrm{He} \mathrm{C}$ : Induction of chromosomal inversion by integration of T-DNA in the rice genome. J Genet Genomics 37: 189-196, 2010.

18. Zhu QH, Ramm K, Eamens AL, Dennis ES and Upadhyaya NM: Transgene structures suggest that multiple mechanisms are involved in T-DNA integration in plants. Plant Sci 171: 308-322, 2006.

19. Yu L, Liu JP, Zhuang JX, Yang LQ, Zhang RL, Ye XM and Cheng JQ: Quantitative analysis of real-time PCR expression production by REST (C) and 2(-Delta Delta C(T)). J Tropical Med 7: 956-968, 2007 (In Chinese).

20. Liu BF, Zhang YM, Yan YQ and Xu XL: Screening transgenic tobacco Byreal-Time fluorescent quantification Pcr technology. J Natural Sci J Harbin Normal Univ 21: 69-72, 2012.

21. Livak KJ and Schmittgen TD: Analysis of relative gene expression data using real-time quantitative PCR and the $2(-\Delta \Delta C T)$ method. Methods 25: 402-408, 2001.

22. Schmittgen TD and Livak KJ: Analyzing real-time PCR data by the comparative C(T) method. Nat Protoc 3: 1101-1108, 2008.

23. Li YY: High performance liquid chromatography applied to the chief ingredients of eucommiaulmoidesoliv and isoflavones in food analysis. Chongqing Southwest Univ: 15-53, 2012.

24. Gu Y: Study of detection of soybean isoflavone using HPLC. Haerbin Northeastern Univ: 1-43, 2011.

25. Ballance GM and Dixon RA: Medicago sativa cDNAs encoding chalcone reductase. Plant Physiol 107: 1027-1028, 2005.

26. Sallaud C, EL-Turk J, Breda C, Buffard D, kozak da I, Wsnault R and Kondorosi A: Differential expression of cDNA coding for chalcone reductase, a key enzyme of the 5-deoxyflavonoid pathway, under various stress conditions in Medicago sativa. Plant Science 109: 179-190, 2005.

27. Young ND, Debellé F, Oldroyd GE, Geurts R, Cannon SB, Udvardi MK, Benedito VA, Mayer KF, Gouzy J, Schoof H, et al: The Medicago genome provides insight into the evolution of rhizobial symbioses. Nature 480: 520-524, 2011.

28. Shimada N, Aoki T, Sato S, Nakamura Y, Tabata S and Ayabe S: A cluster of genes encodes the two types of chalcone isomerase involved in the biosynthesis of general flavonoids and legume-specific 5-deoxy(iso)flavonoids in Lotus japonicus. Plant Physiol 131: 941-951, 2003. 